\title{
The Role of Modeling and Synthesis in Creative Mitigation - ERRATUM
}

\author{
Michael Heilen
}

DOI:10.1017/aap.2020.23, published by Cambridge University Press, July 29, 2020

The corresponding author's mailing address provided in this article (Heilen 2020) is incorrect. The correct mailing address is: Statistical Research Inc., 4306 Mountain View Drive, Haymarket, VA 20169-2123, USA.

The publisher apologizes for the error.

\section{REFERENCE CITED}

Heilen, Michael

2020 The Role of Modeling and Synthesis in Creative Mitigation. Advances in Archaeological Practice 8:263-274 